\title{
Proanthocyanidins from Averrhoa bilimbi fruits and leaves
}

\section{Article}

\section{Accepted Version}

Creative Commons: Attribution-Noncommercial-No Derivative Works 4.0

Ramsay, A. and Mueller-Harvey, I. (2016) Proanthocyanidins from Averrhoa bilimbi fruits and leaves. Journal of Food Composition and Analysis, 47. pp. 16-20. ISSN 0889-1575 doi: https://doi.org/10.1016/j.jfca.2015.12.004 Available at https://centaur.reading.ac.uk/49827/

It is advisable to refer to the publisher's version if you intend to cite from the work. See Guidance on citing.

To link to this article DOI: http://dx.doi.org/10.1016/j.jfca.2015.12.004

Publisher: Elsevier

All outputs in CentAUR are protected by Intellectual Property Rights law, including copyright law. Copyright and IPR is retained by the creators or other copyright holders. Terms and conditions for use of this material are defined in the End User Agreement.

\section{www.reading.ac.uk/centaur}

\section{CentAUR}

Central Archive at the University of Reading

Reading's research outputs online 


\section{Manuscript title: Procyanidins from Averrhoa bilimbi fruits and}

\section{2 leaves}

$4 \quad$ A. Ramsay ${ }^{\text {a* }}$, I. Mueller-Harvey ${ }^{\mathrm{a}}$

5

$6 \quad{ }^{a}$ Chemistry and Biochemistry Laboratory, School of Agriculture, Policy and Development,

7 University of Reading, 1 Earley Gate, P O Box 236, Reading RG6 6AT, U.K

8

9 *Corresponding author (Tel: +44 (0)118 378 6619; Fax: +44 (0)118 935 2421; E-mail:

10 aina.ramsay@hotmail.fr; aina.ramsay@ reading.ac.uk)

11

12

13

14

15 
16 Procyanidins from Averrhoa bilimbi fruits and leaves

17

18 A. Ramsay ${ }^{\mathrm{a} *}$, I. Mueller-Harvey ${ }^{\mathrm{a}}$

19

20

${ }^{\mathrm{a} C h e m i s t r y}$ and Biochemistry Laboratory, School of Agriculture, Policy and Development,

21

University of Reading, 1 Earley Gate, P O Box 236, Reading RG6 6AT, U.K

22

23

*Corresponding author (Tel: +44 (0)118 378 6619; Fax: +44 (0)118 935 2421; E-mail:

24 aina.ramsay@hotmail.fr; aina.ramsay@ reading.ac.uk)

25

26

27

28

29

30

31

32

33

34

35

36

37 


\section{Abstract}

39 Proanthocyanidins from Averrhoa bilimbi fruits and leaves were analysed by thiolysis with benzyl mercaptan and high performance liquid chromatography - mass spectrometry and consisted of pure B-type procyanidins. These tannins consisted of almost pure homopolymers, with epicatechin accounting for most of the monomeric subunits in fruits (97\%) and leaves (99\%). Leaves contained more procyanidins (4.5 vs $2.2 \mathrm{~g} / 100 \mathrm{~g}$ dry weight) with a higher mean degree of polymerisation (9vs 6) than fruits. This study thus contributes information on the proanthocyanidins of a traditional food that can make an important contribution to the intake of compounds with antioxidant and health benefits. The fruits are prized for culinary purposes and the leaves are used in traditional medicine.

Keywords: Averrhoa bilimbi, cucumber tree, food analysis, proanthocyanidins, condensed tannins, gel-NMR, thiolysis, benzyl mercaptan 


\section{Introduction}

53 Investigation into the phytochemical profiles of underutilized and/or wild foods is becoming increasingly important in the context of food security and tree foods are of particular interest, as trees are generally more resilient to periodic droughts and unseasonal weather events than crops. Underutilised foods can be especially valuable when staple foods are in short supply. Information on the contents of non-nutrients is needed to explore their bioactivities and dietary health benefits (Rush, 2001). Therefore, knowledge of the phytochemical composition of wild foods will allow local populations to better exploit local resources and their benefits (Scoones et al. 1992).

Averrhoa bilimbi (L.), commonly called the cucumber tree (Figure 1), belongs to the family of Oxalidaceae and grows in tropical regions (Central America, Asia and Caribbean Islands). The fruits are consumed locally in culinary preparations (fresh in salad or pickled) or as juice. The juice can also be used as a remedy to treat dental disorders, sore throats and stomach problems (Ariharan et al. 2012). Averrhoa bilimbi fruits have shown anti-obesity properties or anti-cholesterolemic activity (Ambili et al. 2009) and also antibacterial and antioxidant activities (Ashok Kumar et al. 2013). However, their high acidity $(\mathrm{pH}=4)$ and high oxalate concentration (Morton et al. 1987) has led to renal failure after prolonged consumption of the juice in humans (Bakul et al. 2013). In terms of phytochemical compounds, the fruits are a good source of vitamin C (Ariharan et al. 2012) and various flavonoids (myricetin, luteolin, quercetin and apigenin) have been quantified (Koo Hui \& Suhaila, 2001). Although the presence of tannins has been mentioned in the fruits (Ashkok Kumar et al. 2013,

73 Hasanuzzaman et al. 2013), to our knowledge, proanthocyanidins have not previously been detected or characterised in A. bilimbi fruits or leaves. The leaves are traditionally used as a paste made with water for dermatological issues (skin rashes, itches, shingles, eczema, pimples) and against rheumatism (Ariharan et al. 2012). This information will be useful for 
77 probing the health benefits of A. bilimbi fruits and leaves, for expanding food databases on 78 proanthocyanidins (websites 1 and 2) and for enabling intake calculations, especially for populations consuming wild tropical and underutilised fruits and vegetables.

\section{Materials and methods}

82

\subsection{General}

Acetone (analytical reagent grade), acetonitrile (HPLC grade), dichloromethane (HPLC grade) and hydrochloric acid (37\%, analytical reagent grade), were purchased from ThermoFisher Scientific Ltd (Loughborough, U.K.); ( \pm )-taxifolin (98\%); benzyl mercaptan (99\%), epicatechin (EC) and catechin (C) ( $\geq 99 \%$ HPLC) were purchased from Sigma-Aldrich (Poole, U.K.). Deionised water was obtained from a Milli-Q System (Millipore, Watford, U.K.).

\subsection{Samples}

Averrhoa bilimbi leaves and fruits were harvested in December 2013 in a private botanical garden in Trois-Rivières, Guadeloupe, France. Any excess humidity was removed with kitchen paper, air-dried for a few hours, protected from direct light and immediately packed in an air-tight glass container and sent to Reading, U.K. by airplane (1-3 days). Upon arrival, leaves and fruits were freeze-dried and finely ground in an impeller SM1 cutting mill (Retsch, Haan, Germany) to pass a $1 \mathrm{~mm}$ sieve. The ground plant material was stored in the dark at room temperature.

\subsection{Extraction and purification}

\subsubsection{Extractable proanthocyanidins}


101 Finely ground fruits (5.3 g) and leaves (5.5 g) were extracted using magnetic stirring for $1 \mathrm{~h}$

102 with acetone/water $(125 \mathrm{~mL} ; 7: 3, \mathrm{v} / \mathrm{v})$ and the solution was separated from the residue after

103 filtration through a Büchner funnel. Acetone was removed under vacuum at $30{ }^{\circ} \mathrm{C}$; the

104 remaining aqueous solution was centrifuged for $3 \mathrm{~min}$ at $2045 \mathrm{x} \mathrm{g}$ and freeze-dried to give the

105 extract (fruits $=1.6 \mathrm{~g}$, yield $=31 \%$; leaves $=0.8 \mathrm{~g}$, yield $=14 \%$ ). Acetone was allowed to

106 evaporate from the plant residue in the fume cupboard overnight and protected from direct

107 light before freeze-drying; these residues were used for the analysis of unextractable

108 proanthocyanidins.

109

110 2.4. Proanthocyanidin analysis

111 2.4.1. Thiolysis of extractable proanthocyanidins

112 Acetone-water extracts $(8 \mathrm{mg})$ were weighed in triplicates into screw cap glass tubes with a

113 stirring magnet. Methanol (1.5 mL) was added followed by methanol acidified with

114 concentrated $\mathrm{HCl}(3.3 \% ; 500 \mu \mathrm{L})$ and benzyl mercaptan $(50 \mu \mathrm{L})$. Tubes were capped and

115 placed into a water bath at $40{ }^{\circ} \mathrm{C}$ for $1 \mathrm{~h}$ under vigorous stirring. The reaction was stopped by

116 placing the tube in an ice bath for $5 \mathrm{~min}$. Distilled water $(2.5 \mathrm{~mL})$ and the internal standard,

117 taxifolin in methanol $(500 \mu \mathrm{L} ; 0.1 \mathrm{mg} / \mathrm{mL})$, were added and thoroughly mixed. The mixture

118 was transferred into a $800 \mu \mathrm{L}$ vial, closed with a crimp top and analyzed by HPLC-MS within

11912 h (Ramsay et al. 2015).

120

121 2.4.2. Thiolysis of in situ and unextractable proanthocyanidins

122 Whole freeze-dried fruits and leaves or the plant residues $(200 \mathrm{mg})$, which remained after the 123 aqueous acetone extraction, were reacted with the thiolysis reagent $(2 \mathrm{~mL}$ methanol, $1 \mathrm{~mL}$ of

$1243.3 \% \mathrm{HCl}$ in methanol, and $100 \mu \mathrm{L}$ benzyl mercaptan) in triplicates as above. After the

125 reaction, methanol $(1 \mathrm{~mL})$ was added to the mixture. The sample was mixed and centrifuged 
at $2727 \mathrm{x}$ g for $3 \mathrm{~min}$ and supernatant $(1 \mathrm{~mL})$ was transferred into another screw cap glass tube. Distilled water $(9 \mathrm{~mL})$ and internal standard, taxifolin in methanol $(500 \mu \mathrm{L} ; 0.1 \mathrm{mg} / \mathrm{mL})$, were added and thoroughly mixed. The mixture was transferred into a vial, closed with a crimp top and analysed by HPLC-MS as soon as possible or within the next $12 \mathrm{~h}$.

\subsection{Liquid chromatography-mass spectrometry (HPLC-MS) analysis}

LC-MS was used to check for the presence of free flavan-3-ols in the plant materials and extract and to confirm the identity of terminal and extension units using an Agilent 1100 Series HPLC system and an API-ES instrument Hewlett Packard 1100 MSD detector (Agilent Technologies, Waldbronn, Germany). Samples (20 $\mu 1)$ were injected into the HPLC connected to an $\mathrm{ACE}_{18}$ column $(3 \mu \mathrm{m} ; 250$ x $4.6 \mathrm{~mm}$; Hichrom Ltd, Theale, U.K.), which was fitted with a corresponding ACE guard column, at room temperature. The HPLC system consisted of a G1379A degasser, G1312A binary pump, G1313A ALS autoinjector, and G1314A VWD UV detector. Data were acquired with ChemStation software (version A 10.01 Rev. B.01.03). The flow rate was $0.75 \mathrm{ml} / \mathrm{min}$ using $1 \%$ acetic acid in water (solvent $\mathrm{A}$ ) and HPLC-grade acetonitrile (solvent B). The following gradient programme was employed: 0-35 $\min , 36 \%$ B; 35-40 min, 36-50\% B; 40-45 $\min , 50-100 \%$ B; $45-55 \min , 100-0 \%$ B; 55-60 min, $0 \%$ B. Eluting compounds were recorded at $280 \mathrm{~nm}$. Mass spectra were recorded in the negative ionisation scan mode between $\mathrm{m} / \mathrm{z}, 100$ and 1000 using the following conditions: capillary voltage, -3000 V; nebuliser gas pressure, $35 \mathrm{psi}$; drying gas, $12 \mathrm{ml} / \mathrm{min}$; and dry heater temperature, $350{ }^{\circ} \mathrm{C}$ (Ramsay \& Mueller-Harvey, 2015). Flavan-3-ols and their benzyl mercaptan adducts were identified by their retention times and characteristic UV-VIS spectra between 220 and $595 \mathrm{~nm}$. Peak areas of flavan-3-ols at $280 \mathrm{~nm}$ were integrated and quantified using molar response factors relative to taxifolin: 0.30 for catechin and epicatechin; 0.26 for their benzyl mercaptan adducts (Gea et al. 2011). This provided information on the 
151 proanthocyanidin composition in terms of \% terminal and \% extension flavan-3-ol units (i.e.

152 molar percentages). It also allowed calculation of the mean degree of polymerisation (mDP),

$153 \%$ procyanidins (PC) and \% cis- and trans-flavan-3-ols (molar percentages) (Gea et al. 2011).

\subsection{Gel-NMR analysis}

156 Samples were prepared as previously described (Grabber et al. 2013). Briefly, finely milled

157 plant material $(50 \mathrm{mg})$ was mixed in DMSO- $d 6(400 \mu \mathrm{L})$ and pyridine- $d 5(100 \mu \mathrm{L})$ and

158 transferred to a $5 \mathrm{~mm}$ NMR tube. ${ }^{1} \mathrm{H}^{-13} \mathrm{C}$ correlation 2D NMR (HSQC) spectra were recorded

159 at $27^{\circ} \mathrm{C}$ on a Bruker Avance III 500 instrument equipped with TopSpin 2.4 software and a 5-

$160 \mathrm{~mm} \mathrm{BBI}{ }^{1} \mathrm{H} /{ }^{13} \mathrm{C}$ gradient probe (Bruker, Coventry, U.K.). Spectral resonances were

161 referenced to the residual signals of DMSO-d6 (2.49 ppm for ${ }^{1} \mathrm{H}$ and $39.5 \mathrm{ppm}$ for ${ }^{13} \mathrm{C}$

162 spectra) using 128 scans.

163

\section{Results and Discussion}

165

166

167

168

169

170

171

172

173

174

175
Averrhoa bilimbi fruits and leaves were analysed by thiolytic degradation with benzyl mercaptan for proanthocyanidin content and composition directly using the ground plant materials (i.e. in situ analysis) and also the aqueous acetone extracts and plant residues that remained from the solvent extractions. The thiolysis reaction released proanthocyanidin terminal units as flavan-3-ols and extension units as benzyl mercaptan derivatives, which were analysed by reverse-phase HPLC-MS (Ramsay \& Mueller-Harvey, 2015). The proanthocyanidin contents and compositions are described in Table 1 for both fruits and leaves. Figures 3 and 4 illustrate the HPLC chromatograms of fruit and leaf proanthocyanidins after thiolysis. The total proanthocyanidin content in fruits is lower than in leaves (2.2 vs $4.5 \mathrm{~g} / 100 \mathrm{~g}$ of dry weight). The average proanthocyanidin polymer size in fruits was also lower (mDP of 6 vs 9) than in leaves [Note: no free flavan-3-ols could be detected in 
the plant materials or extract before thiolysis]. The key finding is that A. bilimbi fruits and

177 leaves contained only pure procyanidins (PC) (Figure 2).

178 Epicatechin accounted for 97\% of the flavan-3-ol units in fruit proanthocyanidins and for

$17999 \%$ of the leaf proanthocyanidins, with catechin accounting for the rest. Catechin and

180 epicatechin occurred as terminal units in fruits and leaves, but epicatechin was the only

181 extension unit. Catechin and epicatechin were assigned to peaks 1 and 2, respectively, at

182 retention times of $23 \mathrm{~min}$ and $27 \mathrm{~min}$ (Figures 3 and 4), with ion fragments at $\mathrm{m} / \mathrm{z}, 289.3$ [M -

$183 \mathrm{H}]^{-}$. The epicatechin-benzyl mercaptan adduct was assigned to peak 3 at a retention time of

$18443 \mathrm{~min}$ and generated ion fragments at $\mathrm{m} / \mathrm{z} 411.3[\mathrm{M}-\mathrm{H}]^{-}$and, after loss of the benzyl

185 mercaptan molecule $(-124 \mathrm{amu})$ at $m / z, 287.2$.

186 Unextractable proanthocyanidins were also investigated as they are often overlooked (Gea et

187 al. 2011), yet their proportion can exceed extractable proanthocyanidins in foods and may

188 thus represent a substantial amount of the dietary polyphenol intake (Pérez-Jiménez \& Torres,

189 2011). In fact, there were higher amounts of unextractable than extractable proanthocyanidins

190 (fruits: 1.3 vs 0.8 , leaves: 3.2 vs 1.3). The mDP values were also higher in the unextractable

191 than the extractable proanthocyanidins (fruits: 6.7 vs 4.6, leaves: 13.7 vs 6.5) and agrees with

192 our previous findings (Gea et al. 2011; Mechineni et al. 2014, Wang et al. 2015).

193 A gel-NMR analysis $\left({ }^{1} \mathrm{H}-{ }^{13} \mathrm{C}\right.$ HSQC $)$ was also applied directly to the milled leaves and

194 fruits in order to verify the results from thiolysis. This analysis revealed distinct signals for

195 procyanidins: signals at 6.7 and $120 \mathrm{ppm}$ could be assigned to H/C-2'/5'/6' and signals at 6.0

196 and 95 ppm were assigned to H/C-6 and H/C-8 (Figure 2). This confirmed that these

197 proanthocyanidins were procyanidins and B-type linkages. The presence of A-type

198 proanthocyanidins would have been indicated by signals at approximately H/C-3 (4.0/66

$199 \mathrm{ppm})$ and H/C-3 (4.5/27.9 ppm) but it was not detected (Appeldoorn et al. 2009). 
Although proanthocyanidins have limited bioavailability and are relatively stable in the

201 gastrointestinal tract (Serra et al. 2010), some evidence exists for their depolymerisation by

202 intestinal microorganisms (Pérez-Maldonado \& Norton et al. 1996; Touriño et al. 2009).

203 Studies have also shown that procyanidins with lower mDP $(<4)$ are most likely absorbed in

204 the colon after metabolisation by the gut microbiota and their metabolites could be detected in 205 the plasma (Kerimi \& Williamson, 2015). Proanthocyanidins and their metabolites can act as 206 antioxidants in vivo (López-Andrés et al. 2013) and modulate key biological pathways in vivo 207 (Nantz et al. 2013; Vertraetan et al. 2013).

\section{Conclusion}

210 This study revealed the presence of pure procyanidins in A. bilimbi fruits and leaves with a 211 moderate average proanthocyanidin size. Epicatechin accounted for $94 \%$ to $97 \%$ of the 212 flavan-3-ol subunits and these polymers had mean degrees of polymerisation that ranged from

2135 to 14. Pure proanthocyanidins are not so common, especially in edible fruits. Therefore $A$. 214 bilimbi fruits and leaves are potentially valuable sources for proanthocyanidins that could be 215 used for future research into their nutritional and health benefits.

\section{Acknowledgements}

218 The authors would to thank Chris Drake, Honorata Ropiak and Christos Fryganas for their 219 support in the laboratory and Mrs Anita Bazir for providing the plant samples.

\section{Funding sources}

222 This work was supported by the European Commission (Marie Curie Initial Training Network) under Grant PITN-GA-2011-289377, “LegumePlus”. 


\section{References}

226 Ambili, S., Subramoniam, A., Nagarajan. N.S. (2009). Studies on the antihyperlipidemic 227 properties of Averrhoa bilimbi fruit in rats. Planta Medicinal, 75, 55-58.

Appeldoorn, M.M., Sanders, M., Vincken, J.P., Cheynier, V., Le Guernevé, C, Hollman, P.C.H., Gruppen, H. (2009). Efficient isolation of major procyanidin A-type dimers from peanut skins and B-type dimers from grape seeds. Food Chemistry, 117, 713-720.

Ariharan, V.N., Kalirajan, K., Meena Devi, V.N., Nagendra Prasad, P. (2012). An exotic fruit which forms the new natural source for vitamin-C. Rasayan Journal of Chemistry, 5, 356235359.

Ashok Kumar, K., Gousia, S.K., Anupama, M., Naveena Lavanya Latha J. (2013). A review on phytochemicals constituents and biological assays of Averrhoa bilimbi. International Journal of Pharmacy and Pharmaceutical Science Research, 3, 136-139.

Bakul, G., Unni, V.N., Seethaleksmy, N.V., Mathew, A., Rajesh, R., Kurien, G., Rajesh, J., Jayaraj, P.M., Kishore, D.S., Jose, P.P. (2013). Acute oxalate nephropathy due to Averrhoa bilimbi fruit juice ingestion. Indian Journal of Nephrology, 23, 297-300.

Gea, A., Stringano, E., Brown, R.H., Mueller-Harvey, I. (2011). In situ analysis and structural 246 elucidation of sainfoin (Onobrychis viciifolia) tannins for high-throughput germplasm screening. Journal of Agricultural and Food Chemistry, 59, 495-503. 
Grabber, J.H., Zeller, W.E., Mueller-Harvey, I. (2013). Acetone enhances the direct analysis

250 of procyanidin- and prodelphinidin-based condensed tannins in Lotus species by the

251 butanol-HCl-iron assay. Journal of Agricultural and Food Chemistry 61, 2669-2678.

Hasanuzzaman, M., Ramjan Ali, M., Marjan, H., Sourov, K., Mohammad Safiqul, I. (2013).

254 Evaluation of total phenolic content, free radical scavenging activity and phytochemical

255 screening of different extracts of Averrhoa bilimbi (fruits). International Current

256 Pharmaceutical Journal 2, 92-96.

Kerimi, A. \& Williamson, G. (2015). The cardiovascular benefits of dark chocolate. Vascular

Pharmacology, 71, 11-15.

Koo Hui, M., Suhaila, M. (2001). Flavonoid (myricetin, quercetin, kaempferol, luteolin, and apigenin) content of edible tropical plants. Journal of Agricultural and Food Chemistry, 49, $3106-3112$.

López-Andrés P., Luciano G., Vasta V., Gibson T.M., Biondi L., Priolo A., Mueller-Harvey I. (2013). Dietary quebracho tannins are not absorbed, but increase the antioxidant capacity of liver and plasma in sheep. British Journal of Nutrition, 110, 632-639.

Mechineni, A., Kommuru, D.S., Gujja, S., Mosjidis, J. A., Miller, J. E., Burke, J. M., Ramsay, growing goats. Veterinary Parasitology, 204, 221-228. 
274 Morton, J. (1987). Bilimbi. In Julia F. Morton, Fruits of warm climates. (p. 128-129). Miami,

275 FL, USA. Website (accessed 1 Oct 2015). https://hort.purdue.edu/newcrop/morton/index.html

276

277 Nantz, M., Rowe, C., Muller, C., Creasy, R., Colee, J., Khoo, C., Percival, S. (2013).

278 Consumption of cranberry polyphenols enhances human $\gamma \delta-\mathrm{T}$ cell proliferation and reduces

279 the number of symptoms associated with colds and influenza: a randomized, placebo-

280 controlled intervention study. Nutrition Journal, 12, 161- 170.

281

282 Pérez-Jiménez, J. \& Torres, J.L. (2011). Analysis of nonextractable phenolic compounds in 283 foods: The current state of the art. Journal of Agricultural and Food Chemistry, 59, 1271328412724.

285

286 Pérez-Maldonado, R. A., \& Norton, B. W. (1996). The effects of condensed tannins from 287 Desmodium intortum and Calliandra calothyrsus on protein and carbohydrate digestion in 288 sheep and goats. British Journal of Nutrition, 76, 515-533.

Ramsay, A. \& Mueller-Harvey, I. (2015). Cassia alata leaves are a good sources of

291 propelargonidins. Natural Product Research

292 (http://dx.doi.org/10.1080/14786419.2015.1108976).

293

294 Rush, D. (2001). Maternal nutrition and perinatal survival. Journal of Health Population and 295 Nutrition, 19, 220-264.

297 Scoones, I., Melnyk, M., Pretty, J.N. (1992). The hidden harvest: wild foods and agricultural 298 systems. A literature review and annotated bibliography. International Institute for 
Environment and Development, London, UK.

300

301 Serra, A., Macia, A., Romero, M.-P., Valls, J., Blade, C., Arola, L. Motilva, M.-J. (2010).

302 Bioavailability of procyanidin dimers and trimers and matrix food effects in in vitro and in

303 vivo models. British Journal of Nutrition, 103, 944-952.

304

305 Touriño, S., Fuguet, E., Pilar Vinardell, M., Torres, J. L. (2009). Phenolic metabolites of

306 grape antioxidant dietary fiber in rat urine. Journal of Agricultural and Food Chemistry, 57,

$307 \quad 11418-11426$

308

309 Vertraeten, S. V., Jaggers, G. K., Fraga, C. G., Oteiza, P. I. (2013). Procyanidins can interact

310 with Caco-2 cell membrane lipid rafts: Involvement of cholesterol. Biochimica et Biophysica 311 Acta, 1828, 2646-2653.

312

313 Wang, Y., McAllister, T. A., Acharya, S. (2015). Condensed tannins in sainfoin: composition, 314 concentration, and effects on nutritive and feeding value of sainfoin forage. Crop Science, 55, 315 13-22.

316

317 Website 1: http://www.ars.usda.gov/SP2UserFiles/Place/80400525/Data/PA/PA.pdf (accessed 31830 Sep 2015).

320 Website 2: http://phenol-explorer.eu/ (accessed 30 Sep 2015). 
Fig. 1. Averrhoa bilimbi fruits.

326

327 Fig. 2. Structure of a procyanidin dimer (catechin- $(4 \rightarrow 8)-$ epicatechin).

Fig. 3. HPLC chromatogram at $280 \mathrm{~nm}$ after in situ thiolysis of proanthocyanidins from Averrhoa bilimbi fruits: 1, catechin; 2, epicatechin; 3, epicatechin-benzyl mercaptan.

Fig. 4. HPLC chromatogram at $280 \mathrm{~nm}$ after in situ thiolysis of proanthocyanidins from 


\section{$347 \quad$ Table 1}

348 Content and composition of in situ, extractable and unextractable proanthocyanidins in Averrhoa bilimbi fruits and leaves ( $\mathrm{n}=3$ ).

\begin{tabular}{|c|c|c|c|c|c|c|c|c|}
\hline \multirow[t]{2}{*}{ Proanthocyanidins } & \multirow[t]{2}{*}{$\begin{array}{c}\text { Content } \\
(\mathrm{g} / 100 \mathrm{~g} \mathrm{DW})\end{array}$} & \multirow[t]{2}{*}{$\mathrm{mDP}$} & \multirow[t]{2}{*}{$\begin{array}{l}\mathrm{PC} \\
(\%)\end{array}$} & \multirow[t]{2}{*}{$\begin{array}{l}\text { cis } \\
(\%)\end{array}$} & \multirow[t]{2}{*}{$\begin{array}{c}\text { trans } \\
(\%)\end{array}$} & \multicolumn{2}{|c|}{$\begin{array}{l}\text { Terminal units } \\
(\%)\end{array}$} & \multirow{2}{*}{$\begin{array}{l}\text { Extension units } \\
\qquad \begin{array}{c}(\%) \\
\text { EC }\end{array}\end{array}$} \\
\hline & & & & & & $\mathrm{C}$ & $\mathrm{EC}$ & \\
\hline In situ & $2.2(0.1)$ & $6.1(0.1)$ & 100 & $96.8(0.2)$ & $3.2(0.2)$ & $3.1(0.2)$ & $13.5(0.5)$ & $83.4(0.2)$ \\
\hline Extractable & $0.8(0.1)$ & $4.6(0.1)$ & 100 & $94.4(0.1)$ & $5.6(0.1)$ & $5.7(0.1)$ & $15.9(0.1)$ & $78.4(0.1)$ \\
\hline \multicolumn{9}{|l|}{ Leaves } \\
\hline In situ & $4.5(0.2)$ & $9.2(0.1)$ & 100 & $99.5(0.1)$ & $0.5(0.1)$ & $0.5(0.1)$ & $10.4(0.1)$ & $89.1(0.1)$ \\
\hline Extractable & $1.3(0.1)$ & $6.5(0.3)$ & 100 & $98.5(0.3)$ & $1.5(0.3)$ & $1.5(0.3)$ & $13.8(0.5)$ & $84.7(0.8)$ \\
\hline Unextractable & $3.2(0.1)$ & $13.7(0.1)$ & 100 & $99.6(0.1)$ & $0.4(0.1)$ & $0.4(0.1)$ & $6.9(0.2)$ & $92.7(0.1)$ \\
\hline
\end{tabular}

349

350 DW: dry weight; mDP: mean degree of polymerisation; PC: procyanidins; C: catechin (a 2,3-trans flavan-3-ol); EC: epicatechin (a 2,3-cis

351 flavan-3-ol); \% represents relative molar percentages. 